Pacific Journal of Mathematics

MAXIMAL IDEALS IN THE NEAR RING OF POLYNOMIALS 


\title{
MAXIMAL IDEALS IN THE NEAR RING OF POLYNOMIALS MODULO 2
}

\section{J. L. BRENNER}

\begin{abstract}
A near ring (or semiring) is a structure with addition and composition. Under addition, the structure is a commutative group. Composition is associative and distributive on one side: $(p+q) \circ r=p \circ r+q \circ r$. An example is the set of polynomials with coefficients from the ring of integers [or indeed from any ring]; composition is ordinary composition of polynomials. Another example is the set of endomorphisms of an abelian group.
\end{abstract}

An ideal in a near ring is, as usual the kernel of a homomorphism. (This definition first appeared in G. Birkhoff's 1934 paper, "On the combination of subalgebras," in Proceedings of the Cambridge Philosophical Society.) For $N=Z_{2}[x, \circ]$, the near ring of polynomials with coefficients from the field $Z_{2}$ of two elements, the ideal structure is more intricate than it is for $Z_{p}[x, \circ](p>2)$. In this article, all maximal ideals in $N$ are found. Unexpectedly, there are just two of them. There are several other proper ideals. A device due to the referee shows how to construct many of them. Application of his idea is given in the following article.

2. Introduction and summary. The definition of "ideal" shows that, if $I$ is an ideal, then

2.1. $I$ is additively closed:

$$
\left\{t_{1} \in I, t_{2} \in I\right\} \Longrightarrow\left\{t_{1}+t_{2} \in I\right\} .
$$

2.2. $N$ admits $I$, in short $I \circ N \subset N$. Explicitly,

$$
\{t \in I, n \in N\} \Longrightarrow\{t \circ n \in I\} .
$$

2.3. Composition contracts on the right, i.e.,

$$
\left\{t \in I, n_{1}, n_{2} \in N\right\} \Longrightarrow\left\{n_{1} \circ\left(n_{2}+t\right)-n_{1} \circ n_{2} \in I\right\} .
$$

THeorem 2.4. Conversely, a subset $I$ is an ideal if it satisfies 1, 2, 3. (This is a known fact.)

The identity for "。” is the polynomial $x$.

Among the results of this article are the following. The set of all polynomials $p$ in $N$ such that $p(0)=p(1)$ is a maximal ideal $V$, 
but there is another one $T$ (Theorem 3.3). Both maximal ideals are principal, i.e., generated by a single element, together with repeated applications of 2.1-2.3. The smallest (the principal) ideal $J$ containing 1 is determined (Theorem 3.9).

3. The maximal ideals. The near ring $N=Z_{2}[x$, o $]$ has just two maximal ideals, $T$ and $V . T$ is the additive closure of

$$
\left\{1, x+x^{2}, x^{3}, x+x^{4}, x+x^{5}, x^{6}, x+x^{7}, x+x^{8}, x^{9}, \cdots\right\},
$$

and $V$ is the additive closure of $\left\{1, x+x^{a}(a>1)\right\}$.

THeOREM 3.1. $V$ is a maximal ideal.

Proof. $\quad V$ is an ideal, since $V$ contains every polynomial $p(x)$ such that $p(0)=p(1)$. With this characterization, $V$ was discovered by $\mathrm{D}$. Doi Watkins, as a student. If an ideal $K$ contains $V$ properly, then $K$ contains $x^{b}$, hence $x$; hence $N$.

LEMMA 3.2. Every maximal ideal contains 1.

Proof. Either a maximal ideal is $V$, or else it contains a polynomial $p(x)$ such that $p(0) \neq p(1)$. Apply 2.2.

THEOREM 3.3. The set $T$ is a maximal ideal.

This theorem is conveniently proved by characterizing $T$ as in 3.5. It is interesting first to note Lemma 3.4 which shows that, if $T$ is an ideal, $T$ is a maximal ideal.

LEMMA 3.4. Let $p(x)$ be any polynomial not in $T$. Then $p(x)=$ $x+q(x), q(x) \in T$.

Proof. Use induction. By successive subtraction of $x^{3 a \pm 1}+x$ or of $x^{3 a}, p(x)$ can be reduced to $x$.

The following characterization of $T$ is due to the referee.

LEMMA 3.5. Let $\theta$ be an imaginary over $Z_{2}$, such that $\theta^{2}+\theta+$ $1=0$. Then $\theta^{3}+1=0$, and $T$ consists of all polynomials $p(x)$ in $Z_{2}[x]$ such that $p(\theta)^{2}+p(\theta)=0$.

Proof. If $p(x)=x^{3 a \pm 1}+x$, then $p(\theta)=0,1$. If $p(x)=x^{3 a}$, then $p(\theta)=1$. The lemma follows, since $T$ is nothing but the additive closure of the polynomials $x^{3 a \pm 1}+x, x^{3 a}, 1$.

I proved that $T$ is an ideal originally in Spring 1969. (That proof 
did not involve imaginaries.) But Lemma 3.5 permits a shorter proof.

LEMmA 3.6. If $\left[x^{2}+x\right] \circ p(\theta),\left[x^{2}+x\right] \circ q(\theta)=0$, then

$$
\left[x^{2}+x\right] \circ(p(\theta)+q(\theta))=0 \text {. }
$$

LEMMA 3.7. If $g(x)$ is any polynomial in $Z_{2}[x]$, then for every $p(x)$ in $T,\left[p(x)^{2}+p(x)\right] \circ g(\theta)=0$.

Proof. If $g(\theta)=0,1, \theta$ this is clear. The only other possibility is $g(\theta)=1+\theta$; but $1+\theta$ is the imaginary conjugate to $\theta:(1+\theta)^{2}+$ $(1+\theta)+1=0$.

LEMMA 3.8. If $f(x), g(x)$ are any polynomials in $Z_{2}[x]$, then for every $p(x)$ in $T, h(\theta)=f \circ(g(\theta)+p(\theta))+f \circ g(\theta)$ has the value 0 or 1 , so that $h(\theta)^{2}+h(\theta)=0$.

Proof. If $p(\theta)=0$, this is clear. If $p(\theta)=1$, then $h(\theta)=f(g(\theta)+1)+$ $f(g(\theta))$. There are only four possibilities: $g(\theta)=0,1, \theta, 1+\theta$. In the last two cases, $h(\theta)=f(\theta)+f(\theta+1)$; thus $h(\theta)=0$ or 1 in all cases.

The proof of Theorem 3.3 is complete.

THEOREM 3.9. Let $J$ be the intersection of $T, V$. As an additive group, $J$ has index 4 in the additive group $N . J$ is the smallest ideal in $N$ containing 1.

Proof. The fact that, as an additive group, the index $N: J$ is 4 is clear: $J$ contains a binomial $x^{b}+x$ or $x^{b}+x^{3}$ for every degree $b>3$. The cosets of $N \bmod J$ are thus represented by $1, x, x^{3}$, $x+x^{3}$. Since $J$ is the intersection of two ideals, $J$ must be an ideal. The main difficulty is to show that, if an ideal contains 1 , it must contain $J$. This is a consequence of the following series of lemmata.

LEMMA 3.10. If an ideal contains 1 , it must contain $x+x^{2}$.

Proof. $(1+x)^{3}-x^{3}=1+x+x^{2}$; see 2.3 .

Lemma 3.11. If an ideal contains $x+x^{2}$, it contains $x^{a}+x^{2 a}$.

Proof. Use 2.2 with $n=x^{a}$.

LEMmA 3.12. If an ideal contains $t$, it contains $t^{a}$. 
Proof. Use 2.3 with $n_{1}=x^{a}, n_{2}=0$.

Lemma 3.13. If an ideal contains $x+x^{2}$, it contains $x+x^{5}, x^{5}+$ $x^{25}, x^{7}+x^{35}$.

Proof. $x+x^{5}=\left(x+x^{2}\right)^{3}-\left(x+x^{2}\right)-\left(x^{2}+x^{4}\right)+\left(x^{3}+x^{6}\right) ; x^{5}+$ $x^{25}=\left(x+x^{5}\right) \circ x^{5} ; x^{7}+x^{35}=\left(x+x^{5}\right) \circ x^{7}$.

Lemma 3.14. If an ideal $I$ contains $x+x^{2}$, it contains $x+x^{7}$.

Proof. There are several steps in the proof.

First, $I$ contains $x+x^{4}$. Next $I$ contains $x^{4}+x^{17}=\left(x+x^{4}\right)^{5}-$ $\left(x^{5}+x^{20}\right)-\left(x^{4}+x^{8}\right)$. Then $I$ contains $x+x^{19}=\left(x^{4}+x^{17}\right)^{3}-\left(x^{12}+x^{51}\right)-$ $\left(x^{5}+x^{25}\right)-\left(x+x^{5}\right)$. Finally, $I$ contains both $x+x^{17}=\left(x+x^{2}\right)+\left(x^{2}+\right.$ $\left.x^{4}\right)+\left(x^{4}+x^{17}\right)$, and $x^{3}+x^{51}$; and hence $I$ contains $x^{7}+x^{19}=\left(x+x^{17}\right)^{3}-$ $\left(x^{3}+x^{51}\right)-\left(x^{7}+x^{35}\right)$.

LEMmA 3.15. The ideal I containing $x+x^{2}$ must contain $x+x^{a}$ for every a prime to 3 .

Proof. It has already been shown that $I$ contains $x+x^{a}$ for $a=$ $2,4,5,7,8,10$. The process of forming successively $\left(x+x^{a}\right)^{3}$ (which are in $I$ for these values of $a$ ) can be used to construct an inductive proof. For example,

$$
\begin{aligned}
& \left(x+x^{5}\right)^{3}-\left(x^{3}+x^{15}\right)-\left(x+x^{7}\right)=x+x^{11} \\
& \left(x^{4}+x^{5}\right)^{3}-\left(x^{12}+x^{15}\right)-\left(x^{2}+x^{14}\right)=x^{2}+x^{13} \equiv x+x^{13}, \\
& \left(x^{2}+x^{7}\right)^{3} \equiv x+x^{16} \\
& \left(x+x^{8}\right)^{3} \equiv x+x^{17} .
\end{aligned}
$$

In each of the last three formulas, the first parenthesis has the form $x^{b}+x^{9-b}$. Using $\left(x^{b}+x^{12-b}\right)^{3}$ for $b=5,4,2,1$, one finds that $x+x^{19}, x+x^{20}, x+x^{22}, x+x^{23}$ are in $I$. In that part of the argument, the only thing needed is the assertion of the lemma for $a=11,13$, $14,16,17$. The inductive proof may be completed by successive applications of this idea.

Lemma 3.16. The ideal I containing $x+x^{2}$ contains also $x^{3}+x^{3 a}$ for every $a$.

Proof. I contains $x^{3}+x^{9}=\left(x^{2}+x^{5}\right)^{3}-\left(x^{6}+x^{15}\right)-\left(x^{3}+x^{12}\right)$. The proof may be completed by induction. Suppose $b=c d$, where $c$ is a power of 3 and $d$ is prime to 3 .

By Lemma $3.15, x+x^{d}$ is in $I$, so $x^{c}+x^{c d}=\left(x+x^{d}\right) \circ x^{c}$ is in $I$ 
also. If $c>9$, then $\left(x^{3}+x^{9}\right) \circ x^{c / 9}=x^{c / 3}+x^{c}$ is in $I$. By induction, then, $x^{3}+x^{27}$, and in general $x^{3}+x^{c}$, is in $I$. But $x^{3}+x^{c d}=\left(x^{c}+x^{c d}\right)+$ $\left(x^{3}+x^{c}\right)$.

This completes the proof of Theorem 3.9.

THEOREM 3.17. The only maximal ideals in $N$ are $T, V$.

Proof. This follows from Theorems 3.2, 3.9.

THEOREM 3.18. Both ideals $T, V$ are principal.

Proof. The generators are respectively $x^{3}, x^{3}+x+1$.

Each of $T, V$ can be used to define other ideals.

4. Other ideals in $Z_{2}[x, \circ]$.

THEOREM 4.1. Let $K$ be an ideal in $N$. The set of polynomials $p(x)$ in $K$ such that $p(1)=p(0)$ is an ideal in $N$.

Proof. Use 2.1-2.3.

LEMmA 4.2. The intersection of ideals in $N$ is an ideal in $N$.

4.1-4.2 yield the following.

TheOREM 4.4. The principal ideal I generated by $x+x^{2}$ is the additive closure of

$$
\left.\left\{x+x^{a} \text { (a prime to } 3\right) ; x^{3}+x^{3 b}\right\} .
$$

Proof. Apply Theorem 4.1 to $J$.

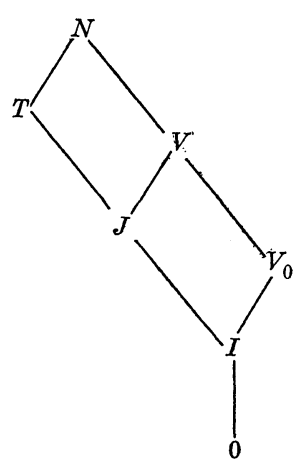

FIG. 1. Inclusion relations for some ideals in $Z_{2}[x, \circ]$. 
The subset of $V$ consisting of polynomials with no constant term is also an ideal, $V_{0}$. See Fig. 1.

5. Conclusion. The succeeding paper shows that there are other ideals in $N$. I am looking forward to the opportunity of reading it.

In $Z_{p}[x, \circ](p>2)$ the ideal structure seems not to be intricate. For example, the only ideal containing 1 is the entire near ring.

Acknowledgment. Thanks are due to the referee for a prompt and careful reading of the manuscript.

Received October 2, 1972 and in revised form November 4, 1972. Research partially supported by NSF Grant GP-32527.

College of Notre Dame, Belmont, Ca.

Present address: 10 Phillips Road

Palo Alto, CA 94303 


\section{PACIFIC JOURNAL OF MATHEMATICS}

EDITORS

RICHARD ARens (Managing Editor)

University of California

Los Angeles, California 90024

\section{R. A. Beaumont}

University of Washington

Seattle. Washington 98105

\section{J. DugundjI}

Department of Mathematics University of Southern California Los Angeles, California 90007

D. Gilbarg and J. Milgram

Stanford University

Stanford. California 94305

\section{ASSOCIATE EDITORS}
E. F. BECKENBACH
B. H. NEUMANN
F. WOLF
K. Yoshida

\section{SUPPORTING INSTITUTIONS}

\author{
UNIVERSITY OF BRITISH COLUMBIA \\ CALIFORNIA INSTITUTE OF TECHNOLOGY \\ UNIVERSITY OF CALIFORNIA \\ MONTANA STATE UNIVERSITY \\ UNIVERSITY OF NEVADA \\ NEW MEXICO STATE UNIVERSITY \\ OREGON STATE UNIVERSITY \\ UNIVERSITY OF OREGON \\ OSAKA UNIVERSITY
}

\author{
UNIVERSITY OF SOUTHERN CALIFORNIA \\ STANFORD UNIVERSITY \\ UNIVERSITY OF TOKYO \\ UNIVERSITY OF UTAH \\ WASHINGTON STATE UNIVERSITY \\ UNIVERSITY OF WASHINGTON

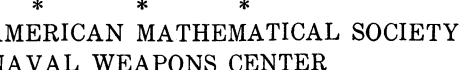

The Supporting Institutions listed above contribute to the cost of publication of this Journal, but they are not owners or publishers and have no responsibility for its content or policies.

Mathematical papers intended for publication in the Pacific Journal of Mathematics should be in typed form or offset-reproduced, (not dittoed), double spaced with large margins. Underline Greek letters in red, German in green, and script in blue. The first paragraph or two must be capable of being used separately as a synopsis of the entire paper. Items of the bibliography should not be cited there unless absolutely necessary, in which case they must be identified by author and Journal, rather than by item number. Manuscripts, in duplicate if possible, may be sent to any one of the four editors. Please classify according to the scheme of Math. Rev. Index to Vol. 39. All other communications to the editors should be addressed to the managing editor, or Elaine Barth, University of California, Los Angeles, California, 90024.

100 reprints are provided free for each article, only if page charges have been substantially paid Additional copies may be obtained at cost in multiples of 50 .

The Pacific of Journal Mathematics is issued monthly as of January 1966. Regular subscription rate: $\$ 72.00$ a year (6 Vols., 12 issues). Special rate: $\$ 36.00$ a year to individual members of supporting institutions.

Subscriptions, orders for back numbers, and changes of address should be sent to Pacific Journal of Mathematics, 103 Highland Boulevard, Berkeley, California, 94708.

\section{PUBLISHED BY PACIFIC JOURNAL OF MATHEMATICS, A NON-PROFIT CORPORATION}

Printed at Kokusai Bunken Insatsusha (International Academic Printing Co., Ltd.), 270, 3-chome Totsuka-cho. Shinjuku-ku, Tokyo 160. Japan.

Copyright (C) 1973 by Pacific Journal of Mathematics Manufactured and first issued in Japan 


\section{Pacific Journal of Mathematics}

\section{Vol. 52, No. $2 \quad$ February, 1974}

Harm Bart, Spectral properties of locally holomorphic vector-valued functions .....

J. Adrian (John) Bondy and Robert Louis Hemminger, Reconstructing infinite

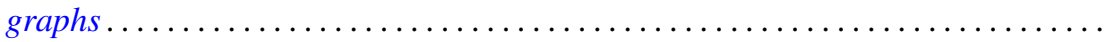

Bryan Edmund Cain and Richard J. Tondra, Biholomorphic approximation of planar

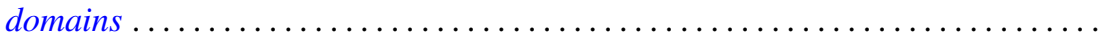

Richard Carey and Joel David Pincus, Eigenvalues of seminormal operators,

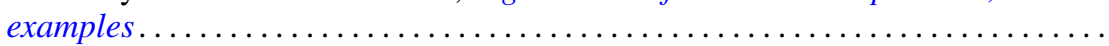

Tyrone Duncan, Absolute continuity for abstract Wiener spaces . . . . . . . . . . . . Joe Wayne Fisher and Louis Halle Rowen, An embedding of semiprime

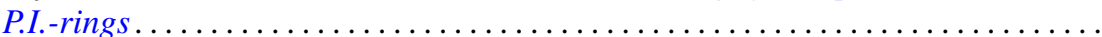

Andrew S. Geue, Precompact and collectively semi-precompact sets of semi-precompact continuous linear operators. . . . . . . . . . . . . . . .

Charles Lemuel Hagopian, Locally homeomorphic $\lambda$ connected plane continua ..... . Darald Joe Hartfiel, A study of convex sets of stochastic matrices induced by

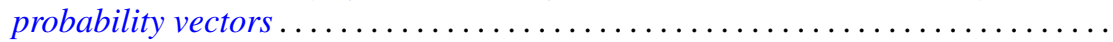

Yasunori Ishibashi, Some remarks on high order derivations $\ldots \ldots \ldots \ldots \ldots \ldots \ldots$ Donald Gordon James, Orthogonal groups of dyadic unimodular quadratic forms.

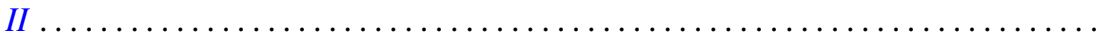

Geoffrey Thomas Jones, Projective pseudo-complemented semilattices . . . . . . . . . Darrell Conley Kent, Kelly Denis McKennon, G. Richardson and M. Schroder,

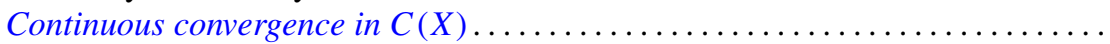

J. J. Koliha, Some convergence theorems in Banach algebras ...

Tsang Hai Kuo, Projections in the spaces of bounded linear oper

George Berry Leeman, Jr., A local estimate for typically real functions . .

475

Andrew Guy Markoe, A characterization of normal analytic spaces by the

homological codimension of the structure sheaf .........

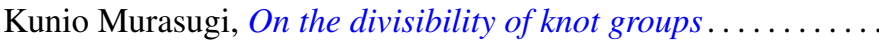

John Phillips, Perturbations of type I von Neumann algebras.

Billy E. Rhoades, Commutants of some quasi-Hausdorff matrices . .

David W. Roeder, Category theory applied to Pontryagin duality

Maxwell Alexander Rosenlicht, The nonminimality of the differential closure .

Peter Michael Rosenthal, On an inversion theorem for the general Mehler-Fock transform pair.

Alan Saleski, Stopping times for Bernoulli automorphisms

John Herman Scheuneman, Fundamental groups of compact complete locally affine complex surfaces. II. ........................

Vashishtha Narayan Singh, Reproducing kernels and operators with a cyclic vector. I. .

Peggy Strait, On the maximum and minimum of partial sums of random variables.

J. L. Brenner, Maximal ideals in the near ring of polynomials modulo 2 .

Ernst Gabor Straus, Remark on the preceding paper: "Ideals in near rings of polynomials over a field" ..........................

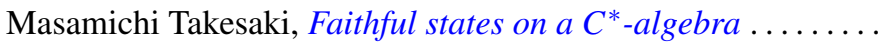

R. Michael Tanner, Some content maximizing properties of the regular simplex.

Andrew Bao-hwa Wang, An analogue of the Paley-Wiener theorem for certain

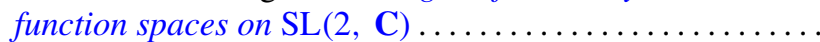

